\title{
Swimming Against the Tide: Primary Care Physicians' Views on Deprescribing in Everyday Practice
}

\author{
Katbarine A. Wallis, MBCbB, $\mathrm{PbD}$, \\ MBHL, FRNZCGP \\ Abby Andrews \\ Michelle Henderson \\ Department of General Practice \& \\ Primary Health Care, University of \\ Auckland, New Zealand.
}

AIC Annals Journal Club selection; see inside back cover or http://www. annfammed.org/AJC/.

Conflicts of interest: authors report none.

\section{CORRESPONDING AUTHOR}

Katharine A. Wallis

Department of General Practice \& Primary Health Care

University of Auckland

Private Bag 92019

Auckland 1142, New Zealand

k.wallis@auckland.ac.nz

\begin{abstract}
PURPOSE Avoidable hospitalizations due to adverse drug events and high-risk prescribing are common in older people. Primary care physicians prescribe most on-going medicines. Deprescribing has long been essential to best prescribing practice. We sought to explore the views of primary care physicians on the barriers and facilitators to deprescribing in everyday practice to inform the development of an intervention to support safer prescribing.
\end{abstract}

METHODS We used a snowball sampling technique to identify potential participants. Physicians were selected on the basis of years in practice, employment status, and practice setting, with an additional focus on information-rich participants. Twenty-four semistructured interviews were audio-recorded, transcribed verbatim, and analyzed to identify emergent themes.

RESULTS Physicians described deprescribing as "swimming against the tide" of patient expectations, the medical culture of prescribing, and organizational constraints. They said deprescribing came with inherent risks for both themselves and patients and conveyed a sense of vulnerability in practice. The only incentive to deprescribing they identified was the duty to do what was right for the patient. Physicians recommended organizational changes to support safer prescribing, including targeted funding for annual medicines review, computer prompts, improved information flows between prescribers, improved access to expert advice and user-friendly decision support, increased availability of non-pharmaceutical therapies, and enhanced patient engagement in medicines management.

CONCLUSIONS Interventions to support safer prescribing in everyday practice should consider the sociocultural, personal, relational, and organizational constraints on deprescribing. Regulations and policies should be designed to support physicians in practicing according to their professional ethical values.

Ann Fam Med 2017;15:341-346. https://doi.org/10.1370/afm.2094.

\section{INTRODUCTION}

$\mathrm{P}$ atient safety and high-value health care are among the greatest challenges facing modern health care systems. Adverse drug events and resultant hospital admissions are common in older people, costing health systems billions of dollars every year. ${ }^{1-3}$ Up to $10 \%$ of hospital admissions result from drug-related problems, two-thirds of which are considered preventable through safer prescribing. ${ }^{4-6}$ The single greatest predictor of adverse drug events is the number of medicines a person is taking. ${ }^{7}$ Polypharmacy is increasing as more people are living longer with more chronic conditions.

Primary care physicians prescribe most ongoing medicines. Despite evidence to guide safe prescribing, high-risk prescribing in older people is common, with 1 in 5 prescriptions potentially inappropriate. ${ }^{8-10}$ Safe prescribing entails regular medicines review, initiating medicines that are indicated, and deprescribing (tapering and withdrawing medicines) when the risks outweigh the potential benefits. ${ }^{11-13}$ While the term "deprescribing" is relatively new, the process of deprescribing has long been essential to best prescribing practice and is a task all primary care physicians are familiar with. ${ }^{14}$ 
The most effective, cost-effective, and practical approach to safer prescribing in everyday practice is not yet known. Interventions that have been tried include audit and feedback, education and training, decision support, pharmacist medicines review, and enhancing patient engagement. ${ }^{15-20}$ Physician input is key to the development of successful interventions. To date, however, there has been relatively little research investigating the views of primary care physicians on deprescribing in everyday practice. Most research has focused on deprescribing in residential care settings, complex case examples, and understanding the views of patients. ${ }^{21-31}$

We sought to explore the views of primary care physicians on the barriers to and facilitators of deprescribing in everyday practice to inform the development of an intervention to support safer prescribing.

\section{METHODS}

This exploratory study used qualitative methodology with a semistructured interview format. Ethical approval was obtained from the University of Auckland Human Participants Ethics Committee (Ref no. 015783).

Primary care physicians were eligible to participate if they were registered to practice in New Zealand at the time of data collection. Participants were identified and recruited through personal and national networks and through a snowball sampling technique. Physicians were invited by e-mail, telephone, or personal contact. To ensure diversity and reduce the risk of bias, participants were selected on the basis of years in practice, employment status, practice setting (rural, suburban, urban), and sex, with an additional focus on information-rich participants.

All 3 researchers conducted the interviews, either face-to-face or by telephone. Interviews ranged from 20 to 90 minutes depending on how much information participants had to share, but were approximately 30 minutes long on average. Interviews were guided by an interview schedule (see Supplemental Appendix 1, available at http://www.annfammed.org/ content/15/4/341/suppl/DC1). Questions explored physicians' understanding of and views on polypharmacy and deprescribing in older people. Participants were asked to speak from their experience in everyday practice. To minimize social desirability biases, participants were informed that they would not be judged or compared. Interview questions were based on the international literature and refined as necessary after the first few interviews to improve clarity and flow. Interviewing continued until saturation was reached ${ }_{i}$ that is, until most of the issues that were being raised had already been mentioned. We conducted a few interviews, transcribed and analyzed them, and then collected more interviews until we determined, at 24 interviews, that we had reached the saturation point. All interviews were audio-recorded with permission and transcribed verbatim.

We used multi-staged coding based on grounded theory to analyze the transcripts. All transcripts were independently read and coded by at least 2 researchers. Codes were assigned to key sections of data to reflect the content. The coding list was built through an iterative process, with new codes being created as necessary by group consent. The few discrepancies identified were resolved through adjudication. When the coding process was complete, we grouped codes with common features in emergent themes, and finally assigned them to 3 overarching themes. ${ }^{32,}{ }^{33} \mathrm{We}$ considered alternative models to describe the relationship between themes but, as facilitators and barriers to deprescribing often mirrored each other, we settled on a consensus model of sociocultural factors, personal or relational factors, and organizational factors as the overarching themes.

\section{RESULTS}

Participants varied in age, sex, experience, and employment status. Participant characteristics are shown in Table 1. In general, participants believed deprescribing was important for safe prescribing in older people. They said, however, that there were many barriers and few incentives to deprescribing in everyday practice.

Table 1. Participant Characteristics $(n=24)$

\begin{tabular}{lc}
\hline Characteristic & Number \\
\hline Sex & 10 \\
Women & 14 \\
Men & \\
Years in practice & 12 \\
More than 20 & 6 \\
10-20 & 6 \\
Less than 10 & \\
Employment status & 11 \\
Partner & 10 \\
Long-term locum & 2 \\
Locum & 1 \\
Trainee (3rd year) & \\
Practice location & 13 \\
Urban & 1 \\
Suburban & 10 \\
Rural & \\
Practice size & 7 \\
Small & 7 \\
Medium & 10 \\
Large & \\
\hline
\end{tabular}




\section{Table 2. Primary Care Physicians' Views on the Barriers to and Facilitators of Deprescribing} in Everyday Practice

\begin{tabular}{|c|c|c|}
\hline \multicolumn{2}{|c|}{ Barriers and Facilitators } & \multirow{2}{*}{$\begin{array}{l}\text { Example Quotations } \\
\text { I think there seems to be an expectation that if they've got a problem they'll be given another } \\
\text { pill to fix it. (GP-9) }\end{array}$} \\
\hline $\begin{array}{l}\text { Sociocultural } \\
\text { factors }\end{array}$ & Patient expectations & \\
\hline & & There are people who see medication as the barrier between them and the grave. (GP-7) \\
\hline & $\begin{array}{l}\text { Medical culture of } \\
\text { prescribing }\end{array}$ & $\begin{array}{l}\text { I guess it's easy to keep adding in medications without looking at whether they need all the } \\
\text { medications they're already on. (GP-21) }\end{array}$ \\
\hline & & $\begin{array}{l}\text { Prescribing is something that's taught a lot, you know. Deprescribing isn't really something } \\
\text { that's been talked about from the get-go. It's not something that's come up. As a GP trainee, } \\
\text { it's not something that we've had a session on. (GP-9) }\end{array}$ \\
\hline \multirow[t]{12}{*}{$\begin{array}{l}\text { Personal and } \\
\text { relational } \\
\text { factors }\end{array}$} & Uncertainty & $\begin{array}{l}\text { We all want to do the right thing, but... We don't know what the combinations of many } \\
\text { conditions and all the medications for each of their conditions, what kind of extra risk that } \\
\text { poses. (GP-8) }\end{array}$ \\
\hline & $\begin{array}{l}\text { Fear of damage to repu- } \\
\text { tation, accountability }\end{array}$ & $\begin{array}{l}\text { You could be viewed as being neglectful, as being a bad doctor, as being not competent, if } \\
\text { you're taking medications away and someone has an event. (GP-5) }\end{array}$ \\
\hline & $\begin{array}{l}\text { for adverse outcomes, } \\
\text { moral blame and shame }\end{array}$ & $\begin{array}{l}\text { We end up putting people on more stuff than I'm really comfortable with, but it's hard to } \\
\text { defend not complying with the guidelines. (GP-15) }\end{array}$ \\
\hline & & $\begin{array}{l}\text { If [the patient] had a heart attack and the doctor in the hospital said "Oh it's because your } \\
\text { [doctor] stopped your statin," then [the doctor] would feel terrible, and so he doesn't stop } \\
\text { them even though he thinks he should. (GP-2) }\end{array}$ \\
\hline & & $\begin{array}{l}\text { The risk that you take on yourself... if the person, say, has a heart attack and you stopped their } \\
\text { statin. So, there's that psychological stuff that goes on. (GP-5) }\end{array}$ \\
\hline & Research, education and & I think we need more research, more collaborations. (GP-3) \\
\hline & training & I think education would be very helpful for us, in sort of just giving us more confidence. (GP-17) \\
\hline & $\begin{array}{l}\text { Maintaining relation- } \\
\text { ships with patients and }\end{array}$ & $\begin{array}{l}\text { It can come off looking like you no longer care about the patient, you know, "You're old } \\
\text { enough to die now so it doesn't really matter." (GP-14) }\end{array}$ \\
\hline & colleagues & $\begin{array}{l}\text { Sometimes people will say, "Why shouldn't I have the same treatment that a younger person } \\
\text { would have? You're just writing me off." (GP-16) }\end{array}$ \\
\hline & & $\begin{array}{l}\text { It's quite difficult to say, "How about we reduce [a medicine]?" when it's only just been started } \\
\text { by somebody else, like a hospital doctor or something. (GP-6) }\end{array}$ \\
\hline & & The reason you don't stop things is you think they [specialists] know better than you. (GP-2) \\
\hline & Ethical duty: beneficence & I think you've got to do what's right for your patient, regardless. (GP-13) \\
\hline
\end{tabular}

Less experienced physicians and those in short-term, low-trust therapeutic relationship in particular reported finding deprescribing challenging. Quotations highlighting participant views on the barriers and facilitators to deprescribing in everyday practice are set out in Table 2 and identified in text by parenthesized participant numbers.

\section{Barriers to Deprescribing in Everyday Practice}

Physicians described deprescribing as "swimming against the tide" (GP-6) of patient expectation, the medical culture of prescribing, and organizational constraints. They said prescribing was the easy option, while deprescribing was time-consuming and came with inherent risks both for themselves and for patients. They said patients expected there to be "a pill for every ill" and that this expectation was exacerbated by directto-consumer advertising of medicines in New Zealand.

Some physicians reported that uncertainty and fear influenced their prescribing and deprescribing decisions. They identified uncertainty regarding which medicines patients were taking and why because of poor information sharing among patients' multiple prescribers; uncertainty and a lack of evidence regarding best prescribing practice in older people with multiple chronic conditions; and uncertainty regarding their knowledge and application of the available evidence. Uncertainty gave rise to fear. They feared the repercussions should a patient suffer a potentially preventable adverse outcome following deprescribing: they feared reputational damage (being seen to be a "bad doctor"-GP-5), accountability repercussions, and moral blame and shame ("feeling terrible"-GP-2). In general, physicians were more fearful of the consequences of deprescribing than of prescribing.

Physicians also reported that their prescribing was influenced by a concern to maintain relationships with patients, patients' families, and colleagues. They feared upsetting patients and their families, who they said could misinterpret the recommendation to deprescribe as a sign that their doctor was giving up on them and trying to save money rather than improve outcomes. Some physicians, especially the younger and less experienced ones, described a professional etiquette that left them reluctant to stop medicines initiated by others. They felt uncomfortable going against the pre- 


\begin{tabular}{|c|c|c|}
\hline \multicolumn{2}{|c|}{ Barriers and Facilitators } & \multirow{2}{*}{$\begin{array}{l}\text { Example Quotations } \\
\text { There is no time ... [You've got] complicated, complex patients and you never have more than } \\
15 \text { minutes and sometimes its double booked. There's never time to spend on this. (GP-2) }\end{array}$} \\
\hline \multirow[t]{19}{*}{$\begin{array}{l}\text { Organizational } \\
\text { factors }\end{array}$} & $\begin{array}{l}\text { Fast pace and competing } \\
\text { demands of practice }\end{array}$ & \\
\hline & & $\begin{array}{l}\text { Patients are not coming in for a deprescribing conversation; they're coming in for something } \\
\text { else like a repeat or to talk about their aching joints. So the deprescribing conversation is an } \\
\text { added thing to the consultation. (GP-5) }\end{array}$ \\
\hline & & $\begin{array}{l}\text { A lot of the time the opportunities for deprescribing are lost by either repeat prescription } \\
\text { generation without seeing the patient or doing their repeat medications in an appointment } \\
\text { where they've come in to talk about something else. (GP-9) }\end{array}$ \\
\hline & & $\begin{array}{l}\text { With the best will in the world we get really busy, we get distracted and we mean to do things } \\
\text { that we don't do. (GP-3) }\end{array}$ \\
\hline & Targeted funding & $\begin{array}{l}\text { You need some funded time with the patient so that you can bring the patient in and say "This } \\
\text { is a special appointment that's not to talk about your current medical problems, it's specifi- } \\
\text { cally about managing your medicines better." (GP-4) }\end{array}$ \\
\hline & $\begin{array}{l}\text { Computer prompts and } \\
\text { alerts }\end{array}$ & $\begin{array}{l}\text { An alert would give you a little bit of courage to do it, or give you more reassurance, or give } \\
\text { you a way to bring it up with the patient like, "Look, you see, the computer has noticed } \\
\text { you're on too many medications, maybe we can reduce it." (GP-2) }\end{array}$ \\
\hline & & Memory support... Prompts are good, helpful. (GP-3) \\
\hline & Fragmentation of care & $\begin{array}{l}\text { As a locum, it's difficult because you don't know the indications, you don't know the patient } \\
\text { very well, you don't know the history. Has someone tried to stop them before and it hasn't } \\
\text { gone well and had to be restarted? (GP-2) }\end{array}$ \\
\hline & & [Deprescribing is difficult] if they don't know me well, haven't built up that trust. (GP-12) \\
\hline & $\begin{array}{l}\text { Information flow between } \\
\text { prescribers }\end{array}$ & $\begin{array}{l}\text { The electronic portals might be something that will make it easier in the future, centralized } \\
\text { storage of information that everyone can access. (GP-9) }\end{array}$ \\
\hline & $\begin{array}{l}\text { Access to expert advice } \\
\text { and user-friendly deci- }\end{array}$ & $\begin{array}{l}\text { I like to ring someone up and just ask them what I should do. I would like to be able to ring a } \\
\text { cardiologist or geriatrician. I often email a pharmacist. (GP-2) }\end{array}$ \\
\hline & sion support & $\begin{array}{l}\text { I've recently come across an app, which I have on my iPad [MedStopper], and you can put in } \\
\text { the medication list there and it will prioritize them for you. So, that's a really neat little tool. } \\
\text { (GP-11) }\end{array}$ \\
\hline & Guidelines & Most guidelines are suggesting you add medicines rather than take them away. (GP-7) \\
\hline & & $\begin{array}{l}\text { In each guideline for each condition, have a section on when it would be appropriate to } \\
\text { reduce or stop each medication. (GP-2) }\end{array}$ \\
\hline & Communication of risk & $\begin{array}{l}\text { They're used to being on these medications; whatever they're feeling in their lives and the } \\
\text { way that they're experiencing their lives, this is their usual way of feeling and they're used } \\
\text { to it. You think that perhaps taking off the statin will make them feel better, but that's a very } \\
\text { subtle thing to try and tell them because most of the time they're not actually feeling bad, } \\
\text { or they don't know they're feeling bad. (GP-1) }\end{array}$ \\
\hline & & Communicating risk to patients, it's very difficult. (GP-14) \\
\hline & $\begin{array}{l}\text { Access to non-pharmaceu- } \\
\text { tical options }\end{array}$ & $\begin{array}{l}\text { It's harder to access other services. Non-pharmaceutical options are often a lot harder to access } \\
\text { than medications. (GP-9) }\end{array}$ \\
\hline & Patient activation & $\begin{array}{l}\text { A recall that sends out something to the patient every year and says, "Next time you're at the } \\
\text { doctor make sure to look over the pills." (GP-8) }\end{array}$ \\
\hline & & [A letter] to warm the patient up ... (GP-3) \\
\hline
\end{tabular}

scribing of the patient's usual doctor and of specialists, both of whom they felt knew better than they did.

The physicians identified many organizational barriers to deprescribing. Top among these was the fast pace and the many competing demands of practice. They said that telephoned repeat prescriptions saved time but came at the cost of opportunities for deprescribing. They said fragmentation of care made deprescribing difficult, not only because of poor information flow between prescribers, but also because of the low levels of trust in short-term therapeutic relationships. They said single-disease-specific guidelines promoted prescribing, not deprescribing; and the limited availability of non-pharmaceutical options, such as psychological therapy, contributed to making prescribing the easy option.

\section{Physician Recommendations for Interventions to Support Deprescribing}

The only incentive to deprescribing that physicians identified was the duty to do what was right for the patient. The physicians recommended a number of organizational changes to support deprescribing in everyday practice. These included targeted funding for annual medicines review, computer alerts to prompt physicians' memories, computer systems to improve information sharing between prescribers, improved access to non-pharmaceutical therapies, research to 
build the evidence base in multimorbidity, education and training, ready access to expert advice and userfriendly decision support, updating guidelines to include advice on when to consider stopping medicines, developing new guidelines for the management of common comorbidities, tools and resources to assist in the communication of risk to patients, and activating patients to become more involved in medicines management and alert to the possibility that less might be better.

\section{DISCUSSION}

This study suggests that the barriers to deprescribing are formidable, ranging as they do from patient expectations and the medical culture of prescribing through fear of bad outcomes and myriad organizational factors, while the sole incentive to deprescribing is the physician's duty to do the right thing for the patient. The physicians recommended a number of organizational changes to support safer prescribing in practice.

Our research contributes to the growing qualitative literature on the factors influencing deprescribing. ${ }^{21-30}$ Many of the suggested organizational changes we identified have previously been described, including targeted funding for annual medicines review, computer prompts and alerts, improving information flows between multiple prescribers, improving access to expert advice and user-friendly decision support, increasing availability of non-pharmaceutical alternatives, enhancing patient engagement in medicines management, and more research, education, and training to reduce the uncertainty in practice..$^{21-30}$

The novel contribution of our research lies in its focus on everyday primary care practice, where most ongoing prescribing occurs, and on the sociocultural influences at play-the importance to physicians of maintaining relationships with both patients and colleagues. Study findings draw attention to the need for a change in culture and in the attitudes and behaviors of both patients and physicians as well as a need to "warm the patient up" to the idea of deprescribing to the possibility that less may be better. Study findings also draw attention to the need to support physicians in practicing according to their professional ethical values. Reducing uncertainty through improved information flows and more research and education is important, but given the "necessary fallibility of a knowledge of particulars," there will always be uncertainty in medicine. ${ }^{34}$ There will always be risk. Older people will always suffer potentially preventable adverse outcomes and in some cases die; relationships can always be damaged. Our study thus draws attention to the need to support physicians in practicing according to their professional ethical values_-in taking on the risk of upsetting patients and of patients suffering potentially preventable adverse outcomes and in tapering and withdrawing medicines regardless when the potential harms start to outweigh the potential benefits.

Strengths of this study include the number and diversity of primary care physician participants. A limitation was the risk of bias with the snowball sampling technique, but this was necessary to ensure diversity in participants and responses and to recruit participants who were good informants ; that is, those who were willing to participate, had time to be interviewed, and were knowledgeable and articulate. While we reassured participants that there were no right or wrong answers and that they would not be judged or compared, it is possible they provided responses that do not accurately reflect their experience in everyday practice.

This research contributes to the growing body of literature on the views of physicians on the barriers to and enablers of deprescribing in everyday practice. Interventions to support safer prescribing should consider the sociocultural influences, the importance to physicians of maintaining relationships, the sense of vulnerability many physicians feel in practice, and the myriad organizational constraints. Given that the only incentive to deprescribing that physicians identified was the duty to do what was right for the patient, it would be logical to design regulations and policies that support physicians in practicing according to their professional ethical values-taking on the risks inherent in deprescribing and doing what was right for the patient, regardless.

To read or post commentaries in response to this article, see it online at http://www.AnnFamMed.org/content/15/4/341.

Submitted September 13, 2016; submitted, revised, January 5, 2017; accepted February 22, 2017.

Key words: primary care; deprescribing; polypharmacy; older people

Funding support: University of Auckland Faculty Research Development Fund.

Prior presentations: Royal New Zealand College of General Practitioners Conference (poster); July 28-31, 2016; Auckland, New Zealand.

Acknowledgements: We would like to acknowledge the physicians who participated in this study.

Supplementary materials: Available at http://www.AnnFamMed. org/content/15/4/341/suppl/DC1/.

\section{References}

1. Taché SV, Sönnichsen A, Ashcroft DM. Prevalence of adverse drug events in ambulatory care: a systematic review. Ann Pharmacother. 2011:45(7-8):977-989.

2. Meier F, Maas R, Sonst A, et al. Adverse drug events in patients admitted to an emergency department: an analysis of direct costs. Pharmacoepidemiol Drug Saf. 2015;24(2):176-186. 
3. Budnitz DS, Lovegrove MC, Shehab N, Richards CL. Emergency hospitalizations for adverse drug events in older Americans. $N$ Engl J Med. 2011;365(21):2002-2012.

4. Hakkarainen KM, Hedna K, Petzold M, Hägg S. Percentage of patients with preventable adverse drug reactions and preventability of adverse drug reactions-a meta-analysis. PLoS One. 2012;7(3): e33236.

5. Thomsen LA, Winterstein AG, Søndergaard B, Haugbølle LS, Melander A. Systematic review of the incidence and characteristics of preventable adverse drug events in ambulatory care. Ann Pharmacother. 2007:41(9):1411-1426.

6. Howard RL, Avery AJ, Slavenburg S, et al. Which drugs cause preventable admissions to hospital? A systematic review. Br J Clin Pharmacol. 2007;63(2):136-147.

7. Fried TR, O'Leary J, Towle V, Goldstein MK, Trentalange M, Martin DK. Health outcomes associated with polypharmacy in communitydwelling older adults: a systematic review. J Am Geriatr Soc. 2014;62 (12):2261-2272.

8. Guaraldo L, Cano FG, Damasceno GS, Rozenfeld S. Inappropriate medication use among the elderly: a systematic review of administrative databases. BMC Geriatr. 2011;11(1):79.

9. Davidoff AJ, Miller GE, Sarpong EM, Yang E, Brandt N, Fick DM. Prevalence of potentially inappropriate medication use in older adults using the 2012 Beers criteria. J Am Geriatr Soc. 2015;63(3):486-500.

10. Opondo D, Eslami $S$, Visscher $S$, et al. Inappropriateness of medication prescriptions to elderly patients in the primary care setting: a systematic review. PLoS One. 2012;7(8):e43617.

11. Scott IA, Hilmer SN, Reeve $E$, et al. Reducing inappropriate polypharmacy: the process of deprescribing. JAMA Intern Med. 2015; 175(5):827-834.

12. Reeve E, Shakib S, Hendrix I, Roberts MS, Wiese MD. Review of deprescribing processes and development of an evidence-based, patient-centred deprescribing process. Br J Clin Pharmacol. 2014; 78(4):738-747.

13. O'Mahony D, O'Sullivan D, Byrne S, O'Connor MN, Ryan C, Gallagher P. STOPP/START criteria for potentially inappropriate prescribing in older people: version 2. Age Ageing. 2015;44(2):213-218.

14. World Health Organization. STEP 6: Monitor (and stop?) the treatment. In: Guide to good prescribing - A practical manual. Geneva, Switzerland: World Health Organization; 1994:79-83.

15. Patterson SM, Cadogan CA, Kerse N, et al. Interventions to improve the appropriate use of polypharmacy for older people. Cochrane Database Syst Rev. 2014;10(10):CD008165-CD65.

16. Duerden M, Avery T, Payne R. Polypharmacy and medicines optimisation: making it safe and sound. London, UK: King's Fund; 2013. Available from: http://www.kingsfund.org.uk/sites/ files/kf/field/field_publication_file/polypharmacy-and-medicinesoptimisation-kingsfund-nov13.pdf.

17. Clyne B, Fitzgerald C, Quinlan A, et al. Interventions to address potentially inappropriate prescribing in community-dwelling older adults: A systematic review of randomized controlled trials. J Am Geriatr Soc. 2016;64(6):1210-1222.

18. Jansen J, Naganathan V, Carter SM, et al. Too much medicine in older people? Deprescribing through shared decision making. BMJ. 2016;353:i2893.
19. Mugunthan K, McGuire T, Glasziou P. Minimal interventions to decrease long-term use of benzodiazepines in primary care: a systematic review and meta-analysis. Br J Gen Pract. 2011;61(590): e573-e578.

20. Tannenbaum C, Martin P, Tamblyn R, Benedetti A, Ahmed S. Reduction of inappropriate benzodiazepine prescriptions among older adults through direct patient education: the EMPOWER cluster randomized trial. JAMA Intern Med. 2014;174(6):890-898.

21. Anderson K, Stowasser D, Freeman C, Scott I. Prescriber barriers and enablers to minimising potentially inappropriate medications in adults: a systematic review and thematic synthesis. BMJ Open. 2014;4(12):e006544.

22. Reeve E, To J, Hendrix I, Shakib S, Roberts MS, Wiese MD. Patient barriers to and enablers of deprescribing: a systematic review. Drugs Aging. 2013;30(10):793-807.

23. Schuling J, Gebben H, Veehof LJG, Haaijer-Ruskamp FM. Deprescribing medication in very elderly patients with multimorbidity: the view of Dutch GPs. A qualitative study. BMC Fam Pract. 2012;13(1):56.

24. Farrell B, Tsang C, Raman-Wilms L, Irving H, Conklin J, Pottie K. What are priorities for deprescribing for elderly patients? Capturing the voice of practitioners: a modified delphi process. PLoS One. 2015;10(4):e0122246.

25. Sinnott C, Mc Hugh S, Browne J, Bradley C. GPs' perspectives on the management of patients with multimorbidity: systematic review and synthesis of qualitative research. BMJ Open. 2013;3(9):e003610.

26. Ailabouni NJ, Nishtala PS, Mangin D, Tordoff JM. General practitioners' insight into deprescribing for the multimorbid older individual: a qualitative study. Int J Clin Pract. 2016;70(3):261-276.

27. Bolmsjö BB, Palagyi A, Keay L, Potter J, Lindley RI. Factors influencing deprescribing for residents in Advanced Care Facilities: insights from General Practitioners in Australia and Sweden. BMC Fam Pract. 2016;17(1):152.

28. Cullinan S, O'Mahony D, Fleming A, Byrne S. A meta-synthesis of potentially inappropriate prescribing in older patients. Drugs Aging. 2014;31(8):631-638.

29. Clyne B, Cooper JA, Hughes CM, Fahey T, Smith SM; OPTI-SCRIPT study team. 'Potentially inappropriate or specifically appropriate?' Qualitative evaluation of general practitioners views on prescribing, polypharmacy and potentially inappropriate prescribing in older people. BMC Fam Pract. 2016;17(1):109.

30. Reeve J, Dickenson M, Harris J, et al. Solutions to problematic polypharmacy: learning from the expertise of patients. Br J Gen Pract. 2015;65(635):319-320.

31. Palagyi A, Keay L, Harper J, Potter J, Lindley RI. Barricades and brickwalls - a qualitative study exploring perceptions of medication use and deprescribing in long-term care. BMC Geriatr. 2016;16(1):15.

32. Thomas DR. A general inductive approach for analyzing qualitative evaluation data. Am J Eval. 2006;27(2):237-246.

33. Braun V, Clarke V. Using thematic analysis in psychology. Qual Res Psychol. 2006;3(2):77-101.

34. Gorovitz S, MacIntyre A. Toward a theory of medical fallibility. Hastings Cent Rep. 1975;5(6):13-23. 